\title{
Chronic pain following Lichtenstein tension free inguinal hernia repair
}

\author{
Abeysekera WYM, De Silva WDD, Vithanage KS, Ranasinghe HKTM, Banagala ASK \\ Colombo South Teaching Hospital, Kalubowila, Dehiwala, Sri Lanka
}

Correspondence: Dr. W.Y.M. Abeysekera;

Mobile: +94 773557099; e-mail: yohan.abeysekera@yahoo.com

\begin{abstract}
Introduction \& Objective: Chronic pain following the repair of inguinal hernia has been a topic of interest in the past few decades, probably due to its significant adverse impacts on the quality of life of the patients who undergo the procedure. In this study we assessed the site, severity and incidence of chronic pain following Lichtenstein tension free inguinal hernia repair and its association with preoperative duration of hernia, presence of preoperative groin pain, presence of inguinoscrotal hernia, type of hernia and several preoperative risk factors for inguinal hernia.
\end{abstract}

Methods: Single unit prospective study conducted for a period of one year in Colombo South Teaching Hospital included patients who underwent standard Lichtenstein tension free inguinal hernia repair. Intervieweradministered pre-designed questionnaire was completed in the preoperative and post-operative stages. Postoperatively, patients were reviewed after 3 months to assess the presence of pain according to the International Association of the Study of Pain (ISAP) criteria. Severity of pain was evaluated with Wong-Baker FACES pain rating scale.

Results: Total of 98 patients underwent surgery but only 80 patients returned for the review. Twenty eight (35\%) patients had pain and all were males. All of them had intermittent pain. Nature of the pain was aching in $71.4 \%$, pricking in $14.3 \%$, burning in $7.1 \%$ and constricting in $7.1 \%$. Pain closer to the pubic tubercle was reported by $28 \%$ while $42 \%$ had pain closer to the mid inguinal point. Pain closer to the umbilicus was reported by $21 \%$ while $7 \%$ had pain over the scrotum. Only $14.3 \%$ were on treatment for the pain, mostly simple oral analgesics. Moderately severe pain was reported by $14 \%$ and rest of them complained of mild pain only. Constipation had a significant association with the incidence of chronic pain following Lichtenstein repair but smoking, preoperative duration of hernia, presence of preoperative groin pain, presence of an inguinoscrotal hernia, type of hernia or the other preoperative risk factors for inguinal hernia, such as weight lifting, chronic cough, prostatism had no statistically significant associations with the incidence of chronic pain following Lichtenstein tension free inguinal hernia repair.

Conclusion: Nearly one third of patients reported varying degree of pain following Lichtenstein tension free inguinal hernia repair but it was a mild aching pain which was tolerable and did not require analgesics in the majority. In most cases, this pain was related to the mid-inguinal point or the pubic tubercle. Constipation showed significant associations with the incidence of pain following Lichtenstein tension free inguinal hernia repair.

Keywords: Post-operative pain, Lichtenstein tension free inguinal hernia repair, Inguinal herniorrhaphy

\section{Introduction}

Chronic pain following inguinal hernia repair has been a topic of interest in the past few decades, probably due to its significant adverse impact on the quality of life of the patient as shown in some previous studies (1). Until Cunningham's cooperative hernia study showed the significance of the chronic pain following herniorrhaphy in 1996 (2), it was considered as an infrequent and insignificant complication after surgery (3). Since then many studies have reported significant prevalence of chronic pain following inguinal hernia repair and some studies have assessed the predisposing factors for chronic pain after inguinal hernia repair. 


\section{Material and Methods}

This was a single unit prospective study conducted over a period of one year. Ninety eight consecutive patients operated for inguinal hernia over a period of one year were included in this analysis.

Operative technique: All patients underwent standard Lichtenstein tension free mesh repair. A $6 \times 11 \mathrm{~cm}$ polypropylene mesh was trimmed to fit the space of the inguinal canal floor, with a slit cut laterally to accommodate the spermatic cord. A closed vacuum drain was used in all cases as a standard procedure to minimize the risk of postsurgical haematoma formation. Skin closure performed with Nylon 2/0 interrupted suture which was removed on the $10^{\text {th }}$ postoperative day. Postoperatively, all patients were observed in the ward for 1-2 days or till the daily drainage was less than $30 \mathrm{cc}$ and discharged. Interviewer-administered pre-designed questionnaire was completed in two stages. In the first stage preoperative data of the hernia, were collected after assessment of the patient. In the second stage, presence of pain was assessed 3 months after the surgery during the clinic visit after a brief examination of the surgical site, the scrotum and the abdomen of the patient. Wong-Baker FACES pain rating scale was used to quantify the severity of the pain. In our study we classified the rating of the pain scale as, 1 - 3 (mild pain), 4 - 5 (moderate pain), 6-7 (moderately severe pain) and 8-10 (severe pain).
Informed written consent was obtained from all patients. SPSS 13 version was used for statistical analysis, and the statistically significant association was determined by applying the Chi-square test. $\mathrm{P}$ value $<0.05$ was considered statistically significant.

\section{Results}

A total of 98 patients ( 95 men) with inguinal herniae were treated by Lichtenstein operation during the year. The mean (range) age of the patients was 54.6 years ( 22 - 80 years). Only 80 patients returned for the review after 3 months. Only 5 patients were operated under general anaesthesia. The remaining 93 patients underwent the operation under spinal anaesthesia. Twenty eight $(35 \%)$ reported pain after 3 months of surgery and the average age of those patients was $51.8 \mathrm{ys}$ and all of them were males.

\section{Timing \& Nature of pain}

All the patients with pain complained of an intermittent pain rather than a continuous pain. Out of the patients with pain, $71 \%$ reported an aching type pain and $14 \%$ complained of a pricking type pain. Pain was of burning type in $7.1 \%$ while a similar proportion reported a constricting type pain (Table 1).

Table 1: Site \& nature of chronic pain following Lichtenstein tension free mesh repair

\begin{tabular}{|c|c|c|c|}
\hline \multicolumn{2}{|c|}{ Site of Pain } & \multirow{2}{*}{$\frac{n(28)}{8}$} & \multirow{2}{*}{$\frac{\%}{28.6}$} \\
\hline A & Over or closer to the pubic tubercle & & \\
\hline $\mathrm{B}$ & Over or closer to the level of deep inguinal ring & 12 & 42.9 \\
\hline $\mathrm{C}$ & Over or closer to the anterior superior iliac spine & 0 & 0 \\
\hline $\mathrm{D}$ & Scrotum & 2 & 7.1 \\
\hline \multirow[t]{2}{*}{$\mathrm{E}$} & Above the level of inguinal ligament and and/or closer to the umbilicus & 6 & 21.4 \\
\hline & Non specific /generalized & 0 & 0 \\
\hline \multicolumn{2}{|c|}{ Nature of the pain } & $\mathrm{n}(28)$ & $\%$ \\
\hline \multicolumn{2}{|c|}{ Aching } & 20 & 71.4 \\
\hline \multicolumn{2}{|c|}{ Pricking } & 4 & 14.3 \\
\hline \multicolumn{2}{|c|}{ Burning } & 2 & 7.1 \\
\hline \multicolumn{2}{|c|}{ Constricting } & 2 & 7.1 \\
\hline
\end{tabular}




\section{Site of pain}

Every patient with chronic pain was specific about the site of the pain and none of them mentioned about a non-specific or generalized pain. Nearly $43 \%$ of patients complained of a pain over or closer to the area of the deep inguinal ring (Site B) (Table 1).

\section{Severity of pain}

In the Wong-Baker FACES pain rating scale only the numbers 2, 3 and 4 were selected by the patients in quantifying the severity of their pain. Number 2 indicated 'Hurts a little bit' and 4 indicated 'Hurts little more'. Number 3 was the severity in between the above two levels. Number 2 and 3 were selected by $42.9 \%(n=12)$ each and number 4 by $14.3 \%$ $(n=4)$. None of them reported a severity beyond number 4. Only $14.3 \%(n=4)$ were receiving a treatment for the pain and in all cases this was limited to simple oral analgesics. None of them received native treatment or used any type of application or invasive treatment for the pain.

\section{Predisposing factors for chronic pain}

Forty eight $(60 \%)$ patients has had preoperative groin pain and among patients with chronic pain, $71.4 \%(\mathrm{n}=20)$ has had a preoperative groin pain but there was no statistically significant association between the preoperative groin pain and the incidence of chronic pain following surgery. Forty four patients had direct inguinal herniae, 30 patients had indirect inguinal herniae and only 6 patients had both types. But the type of hernia and the incidence of chronic pain had no statistically significant association. Preoperative inguinoscrotal hernia did not show a significant association with the incidence of postoperative chronic pain. Out of preoperative risk factors, constipation was the only factor which demonstrated a statistically significant association with the incidence of chronic pain following surgery. Smoking was not significant at 5\% level but significant at $10 \%$ level only. Weight lifting, prostatism or preoperative chronic cough had no statistically significant association with the incidence of chronic pain following Lichtenstein operation (Table 2). Neither the preoperative duration of hernia nor the presence of preoperative groin pain had a statistically significant association with the incidence of chronic pain following Lichtenstein tension free inguinal hernia repair. (Table 3 and Figure).

None of our patients developed mesh infection and / or recurrence during the follow-up period.

\begin{tabular}{|c|c|c|c|c|}
\hline \multirow[b]{2}{*}{ Preoperative duration of hernia } & \multicolumn{2}{|c|}{$\begin{array}{c}\text { Patients without } \\
\text { chronic pain }\end{array}$} & \multicolumn{2}{|c|}{$\begin{array}{l}\text { Patients with } \\
\text { chronic pain }\end{array}$} \\
\hline & $(n=52)$ & $\%$ & $(\mathrm{n}=28)$ & $\%$ \\
\hline - $<6$ months & 8 & 15.4 & 6 & 21.4 \\
\hline - $6 \mathrm{M}-1$ year & 22 & 42.3 & 8 & 28.6 \\
\hline - 1 - 5 years & 18 & 34.6 & 6 & 21.4 \\
\hline - $>5$ years & 4 & 7.7 & 8 & 28.6 \\
\hline Preoperative Inguinoscrotal hernia & 18 & 34.6 & 6 & 21.4 \\
\hline Pre-op pain groin pain & 28 & 53.9 & 20 & 71.4 \\
\hline \multicolumn{5}{|l|}{ Type of hernia } \\
\hline - Direct & 28 & 53.9 & 16 & 57.1 \\
\hline - Indirect & 20 & 38.5 & 10 & 35.7 \\
\hline - Direct \& Indirect & 4 & 7.7 & 2 & 7.1 \\
\hline
\end{tabular}




\begin{tabular}{lllll}
$\begin{array}{l}\text { Table 3: Preoperative risk factors for chronic pain following Lichtenstein } \\
\text { tension free mesh repair. }\end{array}$ \\
\hline $\begin{array}{l}\text { Preoperative risk } \\
\text { factors for hernia }\end{array}$ & \multicolumn{3}{c}{$\begin{array}{c}\text { Patients without } \\
\text { chronic pain }\end{array}$} & $\begin{array}{c}\text { Patients with } \\
\text { chronic pain }\end{array}$ \\
\hline & $(\mathrm{n}=52)$ & $\%$ & $(\mathrm{n}=28)$ & $\%$ \\
Smoking & 16 & 30.8 & 14 & 50.0 \\
Wt lifting & 28 & 53.9 & 20 & 71.4 \\
Constipation & 20 & 38.5 & 18 & 64.3 \\
Prostatism & 4 & 7.7 & 4 & 14.3 \\
Chronic cough & 14 & 26.9 & 8 & 28.6 \\
\hline
\end{tabular}

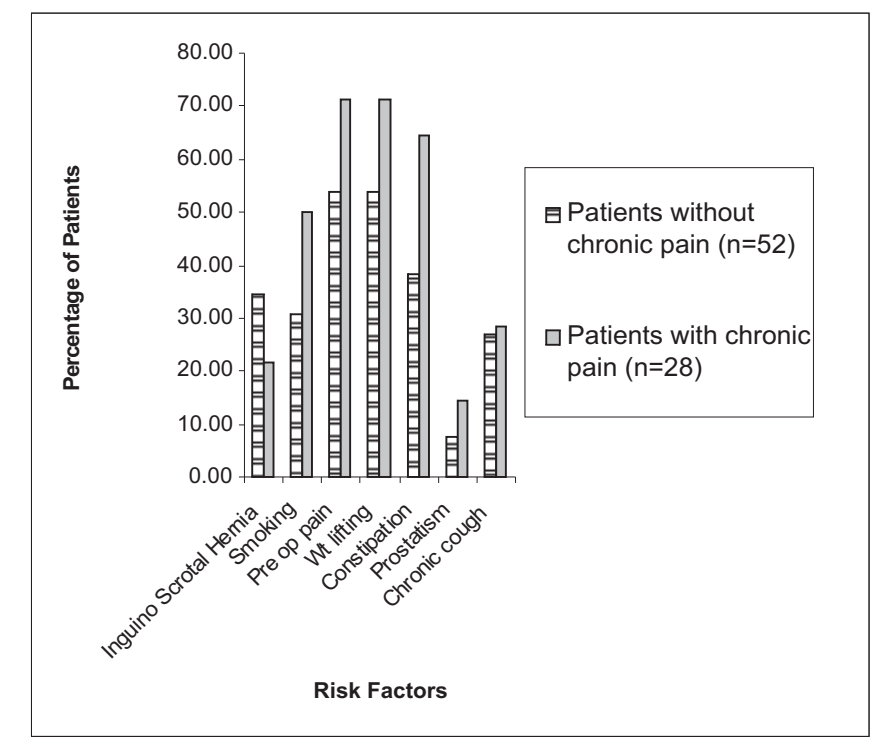

Figure: Preoperative risk factors for chronic pain following Lichtenstein tension free mesh repair

\section{Discussion}

The incidence of chronic pain reported in the current literature varies widely. This is probably due to the differences in the technique of surgery, method of assessment of pain, and the duration of follow up. Assessment of pain after three months may indicate a higher prevalence than assessment at six months or one year. In one of the critical reviews on chronic pain following inguinal hernia repair between 19872000, Poobalan et al, reported a much higher occurrence of pain as of $54 \%$ (4), but in 2004, Aasvang and Kehlt, reported a occurrence of $12 \%$ of chronic pain (5) and a similar occurrence was reported by Simon et al, in 2007 after a meta-analysis of 29 good quality studies (6).
Definition of chronic pain was another controversial issue in many studies. Some have explained it as pain which persists for more than a year postoperatively (7). Another study has defined it as groin or scrotal pain which lasts for more than a month after surgery (8). According to the IASP (International Association of the Study of Pain) definition any pain which persists beyond a period of 3 months can be labeled as chronic pain (9). We defined chronic pain according to this IASP definition and some other studies have also used the same definition (4).

Quantification of the severity of the pain was the next challenging issue. This probably has led to the wide range of prevalence of chronic pain reported in various studies. In studies where a Visual Analog 
Scale (VAS) was used as the tool of pain measurement the incidence of chronic pain was much higher than the studies where simple questions were used as to whether the pain is present or not (6). We used The Wong-Baker FACES (WBF) pain rating scale, to quantify the severity of pain. This scale was originally designed for paediatric patient groups (10), but was later used for adults. We believe that even for adults, it would be much easier to use a pain rating scale with an illustration for a better understanding of the severity of pain than a scale with numbers and / or lines.

The technique of inguinal hernia repair has seen many modifications since the introduction of the modern concept of inguinal hernia repair by Bassini in1884. It has evolved into the laparoscopic surgery which has indicated a better outcome and less postoperative acute and chronic pain when compared with open-repair of the hernia with or without a mesh (6). But still some authorities recommend the open mesh repair over the laparoscopic repair for inguinal hernia (11).

Preoperative and postoperative factors which may increase the risk of chronic pain following inguinal herniotomy have been assessed in some studies. There is a higher risk with recurrent hernias, patients with previous abdominal surgery, younger patients and patients who had a preoperative groin pain related to the hernia $(6,12)$.

Nociceptive pain due to sutures in the periosteum during Lichtenstein mesh repair is a probable risk factor (13). The risk of damaging the genitofemoral and ilioinguinal nerves during the mesh repair has been considered as a risk factor in some studies (14). Supportive evidence has been provided in another study where the elective ilioinguinal and iliohypogastric nerve resection causing less postoperative persistent pain syndrome (15). Light weight mesh has shown some effect in reducing the incidence of chronic pain (16).

\section{Conclusion}

Nearly one third of patients reported pain following Lichtenstein tension free inguinal hernia repair, but mostly it was a mild aching pain which was tolerable and not requiring analgesics. In most instances this pain was related to the mid inguinal point and/or pubic tubercle.
The preoperative duration of hernia, presence of preoperative groin pain, presence of an inguinoscrotal hernia or the type of hernia had no significant association with the occurrence of pain. Except for constipation, rest of the risk factors for inguinal hernia formation, such as smoking, weight lifting, chronic cough, prostatism had no significant association with the incidence of chronic pain following Lichtenstein tension free inguinal hernia repair.

\section{Acknowledgements}

The authors would like to thank Mrs. W.W.M. Abeysekera, MSc (Applied Statistics) currently reading for $\mathrm{PhD}$ (Theoretical Statistics) Latrobe University, Melbourne, Australia, for the invaluable support in statistical analysis of the study.

To all the patients for their contribution to this study, House Officers, Resident House Officers and the nursing staff of surgical wards 11 and 27 of Colombo South Teaching Hospital.

\section{References}

1. Wantz GE. Testicular atrophy and chronic residual neuralgia as risks of inguinal hernioplasty. Surg Clin North Am 1993; 73: $571-81$.

2. Cunningham J, Temple WJ, Mitchell P, Nixon JA, Preshaw RM, Hagen NA. Cooperative hernia study. Pain in the post repair patient. Ann Surg 1996; 224: 598-602.

3. Starling JR, Harms BA, Schroeder ME, Eichman PL. Diagnosis and treatment of genito-femoral and ilioinguinal entrapment neuralgia. Surgery 1987; 102: 581-6

4. Poobalan AS, Bruce J, Smith WC, King PM, Krukowski ZH, Chambers WA. A review of chronic pain after inguinal herniorrhaphy. Clin J Pain 2003; 19: 48-54.

5. Aasvang E, Kehlet H. Chronic postoperative pain: the case of inguinal herniorrhaphy. Br J Anaesth 2005; 95: 69-76.

6. Nienhuijs S, Staal E, Strobbe L, Rosman C, Groenewoud H, Bleichrodt R. Chronic pain after mesh repair of inguinal hernia: a systematic review. Am JSurg 2007; 194: 394-400.

7. MRC Laparoscopic Groin Hernia Trial Group. Laparoscopic versus open repair of groin hernia: a randomised comparison. Lancet 1999; 354: 185-90. 
8. Juul P, Christensen K. Randomized clinical trial of laparoscopic versus open inguinal hernia repair. Br J Surg 1999; 86: 316-9.

9. Merskey H, Bogduk N. Classifications of chronic pain: Description of chronic pain syndromes and definition of pain terms. Report by the International Association for the Study of Pain Task Force on Taxonomy In: Merskey H, Bogduk N, editor. Seattle: IASP Press; 1994: 209-14.

10. Hockenberry MJ, Wilson D, Winkelstein ML: Wong's Essentials of Pediatric Nursing, ed. 7, St. Louis, 2005, p.1259.

11. National Institute for Clinical Excellence. Guidance on the use of laparoscopic surgery for inguinal hernia. Technology appraisal guidance no. 18. London: NICE, 2001.

12. Wilder-Smith $\mathrm{OH}$. Changes in sensory processing after surgical noiciception. Curr Rev Pain 2000; 4: 234-41.
13. Lau H, Patil NG, Yuen WK, Lee F. Prevalence and severity of chronic groin pain after endoscopic totally extra peritoneal inguinal hernioplasty. Surg Endosc 2003; 17: 1620-3.

14. Bringman S, Ramel S, Heikkinen TJ, Englund T, Westman $\mathrm{B}$, Anderberg B.Tension-free inguinal hernia repair: TEP versus mesh-plug versus Lichtenstein: a prospective randomized controlled trial. Ann Surg 2003; 237: 142-7.

15. Tsakayannis DE, Kiriakopoulos AC, Linos DA. Elective neurectomy during open, 'tension free' inguinal hernia repair. Hernia 2004; 8: 67-9.

16. O'Dwyer PJ, Kingsnorth AN, Molloy RG, Small PK, Lammers B, Horeyseck G. Randomized clinical trial assessing impact of a lightweight or heavyweight mesh on chronic pain after inguinal hernia repair. Br J Surg 2005; 92 : 166-70. 